\title{
IMPROVING THERMAL WITHSTANDING CAPACITY OF THREE PHASE INDUCTION MOTOR USING NWCC METHOD
}

\author{
Banti Khan*1, Ashita Goyal $^{2}$, Asst. Prof. Ashutosh Kumar Chobey ${ }^{3}$ \\ ${ }^{* 1}$ School of Energy and Environment Studies, DAVV, INDIA \\ ${ }^{2}$ School of Computer Science and IT, DAVV, INDIA \\ ${ }^{3}$ Department of Electrical and Electronics Engineering, CDGI Indore, INDIA \\ *Correspondence Author: yuvrajmax20@gmail.com
}

\section{Abstract:}

Three phase induction motors are widely used in industries due to their various technical as well as economical advantages. About $60 \%$ of industrial electricity is consumed by these motors, but the heat generation inside the motor due to various losses is a critical factor which degrades the dielectric properties of insulation and shortening the lifespan of motor. This paper presents the capillary based water cooling method of three phase squirrel cage induction motor. In this method, a jacket of capillaries made of jute and cotton is used as a outer cover for the motor casing. A small air gap passage is provided in between motor casing and inner surface of jacket. Natural Water Cooling Capillaries (NWCC) method is used to lower down the surrounding temperature of motor which reduces heating limitations of motor. For this purpose we select a $1.1 \mathrm{~kW}$ three phase, $50 \mathrm{~Hz}$ squirrel cage induction motor. Heat run test is performed on this motor to determine the total loss of energy dissipated as heat on three phase squirrel cage induction motor with and without adopting capillary based water cooling method. Comparison is done on the basis of experimental result which shows that the temperature withstanding capacity of induction motor will increase by $15.5 \%$ after adopting capillary based water cooling method. This is an economical method and no external energy is required for cooling purpose.

Keywords:

Squirrel cage induction motor; dielectric properties; heat run test; temperature withstanding capacity; capillaries; water cooling.

\section{INTRODUCTION}

Most common AC motor found in industrial application is the three phase squirrel cage induction motor of Totally Enclosed Fan Cooled (TEFC) type. For a particular load, these motors are often driven by variable voltage and variable frequency inverters as a result we can achieve variable speed and variable torque control, but the pay-off for that will be an increase in operating temperature conditions ${ }^{[1]}$. All electrical rotating machines generate heat as a result of electrical and mechanical losses inside it. Rise in temperature due to heat is one of the sources of increased stress on induction motor's insulation ${ }^{[2]}$.There is a well-known fact that the operating temperature of an electric machine has a very strong relationship with the life duration of insulation and both 


\section{INTERNATIONAL JOURNAL of RESEARCH -GRANTHAALAYAH

are inversely proportional. So, cooling is necessary for continuous heat removal from motors. Most commonly used motors are TEFC type which is provided with an external forced air cooling fan mounted on the Non-Driven End (NDE) of the shaft with cooling ribs running axially along the outer surface of motor frame ${ }^{[3]}$. Some limitations of this type of air cooling systems are- This type of air cooling is effective only along the axis of rotor but it cannot remove the motor's surrounding heat and the heat transfer coefficient of air is too low to reduce excessive heat from motors. With increase in motor's power rating, dimension of rotor increases but heat removal rate decreases ${ }^{[4]}$.

To achieve a higher power to dimension ratio, a highly effective cooling and ventilation system is required which can ensure sufficient heat removal from the inner side of motor. Substantial improvement can be achieved by adopting direct water cooling methods which ensure relatively low temperature of stator. Following water cooling techniques for induction motor are usually in practice:

1) Water cooled model for three phase induction motor using thermography technique ${ }^{[5]}$.

2) Totally enclosed water cooled method for squirrel cage induction motor ${ }^{[6]}$.

3) Twin water cooled wheel design for cooling of induction motor ${ }^{[7]}$.

4) Forced cooling by stator mounted water pipes ${ }^{[4]}$.

The above four methods are forced water cooling methods which requires external energy for functioning. While in this paper, the thermal withstanding capacity of a three phase induction motor is improved by using Natural Water Cooling Capillaries (NWCC) method which does not require big external heat exchanger as well as external energy for cooling. Water absorbed by capillaries creates natural ventilation system which lower down the temperature of motor's surrounding. Materials and methods adopted are described in section 2 and experimental results are discussed in section 3 .

\subsection{Mechanisms of Heat Generation inside an Electrical Induction Motor}

All rotating electrical machines dissipate heat as a result of electrical and mechanical losses, inside the machines. Losses are higher during the process of starting of motor and dynamic braking and are increases with loading ${ }^{[8]}$. The mechanism of heat generation in induction motors are classified into four groups, mainly related to the places where losses occur. These are joule losses, iron losses, stray losses and mechanical losses ${ }^{[9]}$.

- Joule losses: This mechanism corresponds to the conversion of electrical energy into thermal energy. These types of losses are directly related to electric resistance of the conductor and changes proportionally to the square of the current which is represented by equation as ${ }^{[10]}$ :

$$
\mathrm{P}_{\mathrm{j}}=\mathrm{I}^{2} * \mathrm{R}
$$

Energy conversion by joule effect in squirrel cage induction electric motors occurs in the stator (copper windings) and in the squirrel cage (aluminium bars). 


\section{INTERNATIONAL JOURNAL of RESEARCH -GRANTHAALAYAH \\ A knowledge Repository}

Science

- Iron losses: These losses are due to the conversion of electric energy into thermal energy in the iron. They are divided in the hysteresis and Foucault (eddy currents) losses. The eddy current losses are joule losses that occur in the flow of an induced electric current. The hysteresis losses are due to the energy expended to align the iron magnetic poles to the applied magnetic field ${ }^{[11]}$.

- Stray load losses: The stray load losses are minor losses in the electric motor operation and their quantification is very difficult ${ }^{[12]}$. This includes the losses due to the skin effect, high frequency among others that are unknown or not easily quantified.

- Mechanical losses: These losses comprise the conversion of the mechanical energy into thermal energy due to mechanical friction. Here includes mainly the losses due to rolling bearings (ball/ring interface) and the cooling fan losses.

\subsection{Heat Transfer Mechanisms in Induction Motor}

The transfer mechanism of heat, which is generated as a result of various losses in motor, is discussed here. All three main transfer mechanisms conduction, convection and radiation are involved in the heat exchange of three phase squirrel cage induction motor is described below.

- Conduction: In the solid part of motors such as rotor and stator, heat is typically transferred by conduction. It is an energy transferred due to the temperature difference by the mechanism of intermolecular interactions. The flow of heat by conduction occurs via collision between atoms and molecules and subsequent transfer of kinetic energy ${ }^{[13]}$. Hence, for this part standard Fourier's law is used to connect the heat flux and the temperature gradient, given by equation as:

$$
\mathrm{Q}=\lambda \mathrm{A} \nabla \mathrm{T}
$$

Where $\mathrm{Q}$ presents heat flow, $\lambda$ is the thermal conductivity of material, $\mathrm{A}$ is surface area and $\nabla \mathrm{T}$ is temperature gradient.

- Convection: It is an energy transferred due to temperature difference because of combined mechanisms of intermolecular interactions and bulk transport of heat in air medium. This temperature difference will cause force convection on the frame of motor where the air does not flow on its own but it is rather pushed. There are other parts of motor where convection mode for the energy transfer is used as heat transfer in the air gap, from shaft, from the rotor, shaft ends, magnetic bearings in the cooling duct, and in the end winding space ${ }^{[14]}$. The expression for the flux of such forced convection is given in the form:

$$
\mathrm{Q}=\alpha \mathrm{A}_{s} \Delta T
$$

Where $\alpha$ presents heat transfer coefficient, $\mathrm{A}_{\mathrm{s}}$ is the surface area from which convection is occurring and $\Delta T$ defines temperature difference. 


\section{INTERNATIONAL JOURNAL of RESEARCH -GRANTHAALAYAH

- Radiation: A part of heat in induction motor is transferred by radiation. The actual amount of energy transferred in the form of electromagnetic waves depends not only on the emissivity properties of a part of the motor under consideration, but also on the temperature itself. Due to the temperature difference between the motor surface and the ambient temperature, the heat will be radiated out from the whole of motor surface and the energy radiated can be evaluated according to the Stefan -Boltzmann law of radiation ${ }^{[15]}$ :

$$
\mathrm{Q}=\varepsilon \sigma A\left(\mathrm{~T}_{\mathrm{s}}^{4}-\mathrm{T}^{4} \text { sur }\right)
$$

$\varepsilon$ presents surface emissivity, $\sigma$ is Stefan- Boltzmann constant and its value is $5.67 * 10^{-8}$ $\mathrm{W} / \mathrm{m}^{2} \mathrm{~K}^{4}, \mathrm{~T}_{\mathrm{s}}$ is the temperature of surface and $\mathrm{T}_{\text {sur }}$ is the temperature of surroundings.

\subsection{Effect of Heat on Thermal Withstanding Capacity of Induction Motor}

The major issue which shortens the motor's life is heat. The insulation type used in an electric motor depends on the temperature at which motor will operate. Every insulating material has a certain working temperature complying with the expected life of the motor and allowing it to safely function within this expected period. Even a small increase in temperature can considerably decrease the working life of insulating material. According to the $10^{\circ} \mathrm{C}$ rule, the life of insulation system is halved for each additional $10^{0} \mathrm{C}$ in the temperature at which it is exposed ${ }^{[16]}$.

According to IEC 60085 standards, the insulating materials used in electric motors can be classified into four thermal classes that is class A, class B, class F and class H. Figure 1 shows the use of insulation system verses the temperature rise by means of thermal classification of insulating materials used. Proper cooling techniques must be chosen and working temperature of certain parts of motor must be stable. 


\section{INTERNATIONAL JOURNAL of RESEARCH -GRANTHAALAYAH

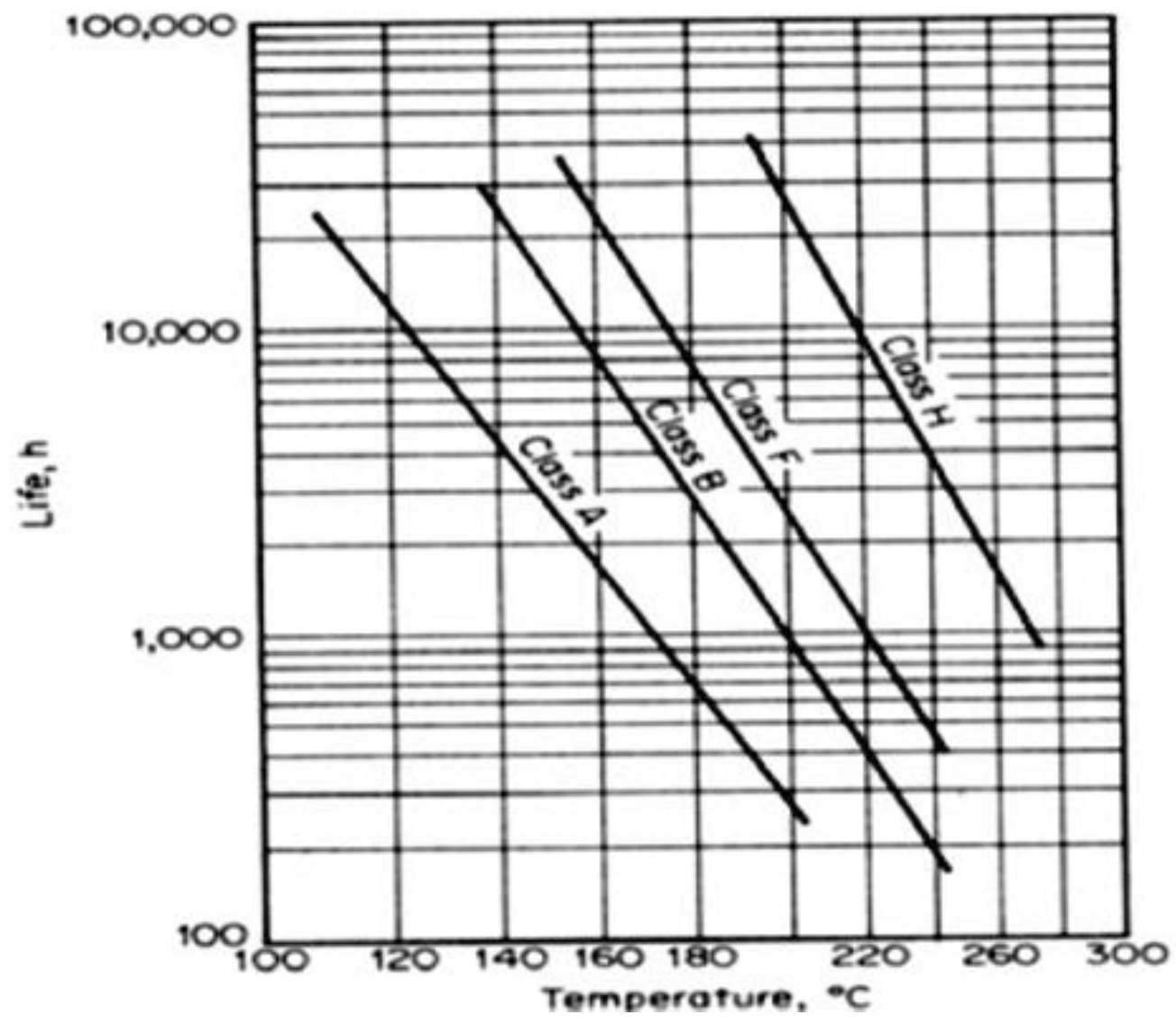

Figure 1. Insulation life versus temperature rise.

\section{MATERIALS AND METHODS}

This section provides an overview of experimental setup of NWCC method. For this purpose a three phase induction motor and its specifications are given in table 1.

Table 1: Specification of Three Phase Induction Motor

\begin{tabular}{|l|l|}
\hline Parameters & Ratings \\
\hline Power & $1.1 \mathrm{~kW}$ \\
\hline Speed & $1450 \mathrm{rpm}$ \\
\hline Current & $3.45 \mathrm{~A}$ \\
\hline Voltage & $415 \mathrm{~V}$ \\
\hline Frequency & $50 \mathrm{~Hz}$ \\
\hline
\end{tabular}




\section{INTERNATIONAL JOURNAL of RESEARCH -GRANTHAALAYAH \\ A knowledge Repository}

Science

Most of the losses occur in the stator part of motor and this is the major source of heat dissipation. By the conduction, convection and radiation modes of heat transfer, heat reaches to the outer casing of motor and is uniformly distributed which results in rise in temperature of surrounding. NWCC method is used to reduce this temperature and acts as a safeguard for the protection of insulation material, to increase the thermal withstanding capacity as well as life of motor. In this method, a capillary jacket is used which is placed above the casing of motor. Figure 2 shows the structure of capillary jacket which is a hollow cylindrical structure, its inner layer is made by porous mat of tatties matrix (used in evaporative coolers).

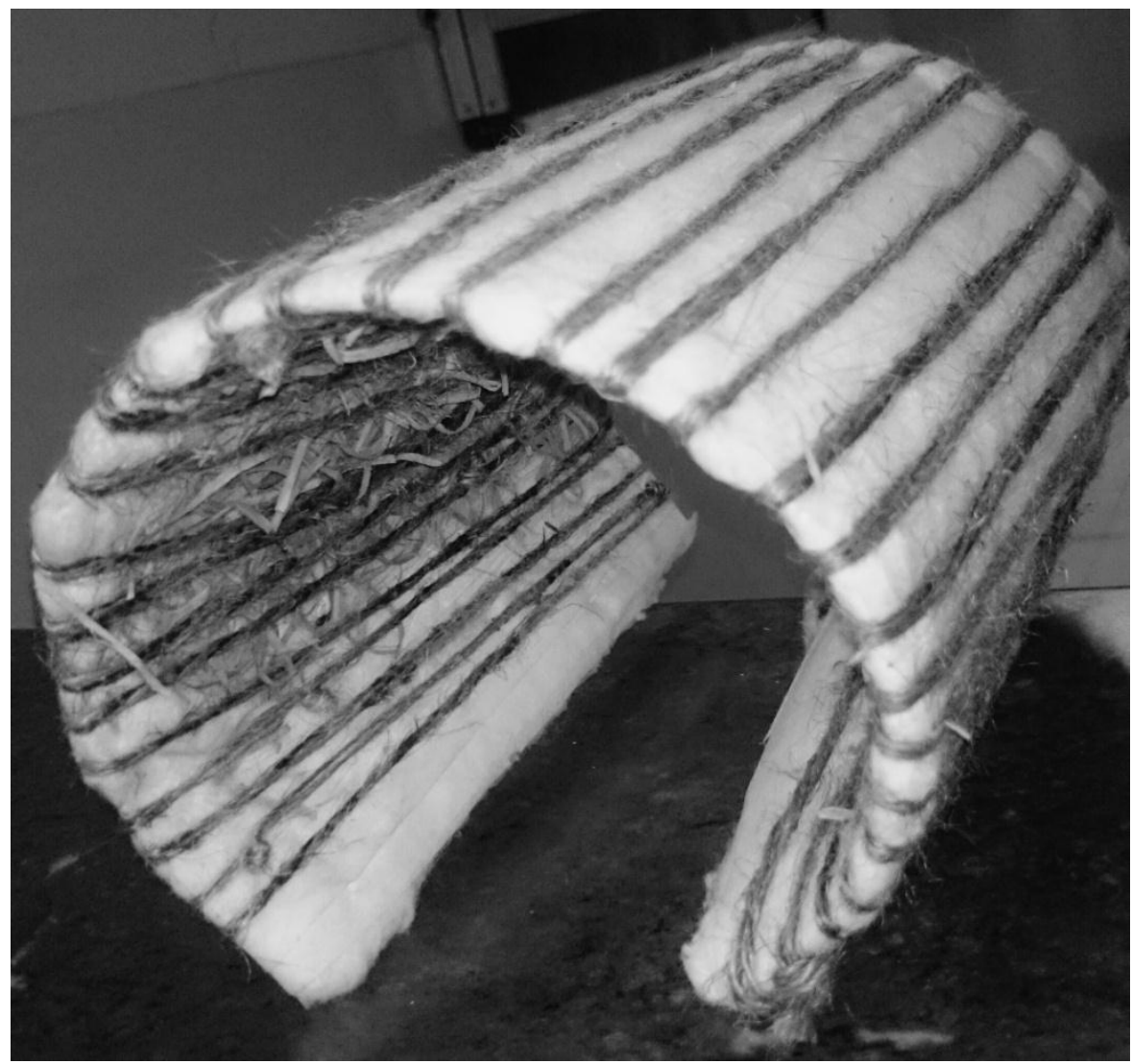

Figure 2: Structure of capillary jacket.

Capillary jacket is comprised of three layers. First layer is of Tatties matrix which has a property of high temperature withstanding capability. So, its main function is to protect the jacket's capillaries from overheating of motor and also provide structural support. Middle layer of jacket is made of cotton material which is wrapped on the layer of tatties matrix. Main function of middle layer is to provide uniformity to capillary effect. Top most layer of jacket is of capillary structure. Capillaries are made by jute and cotton materials which are attached on the outer surface of jacket. Composition of jute fiber ${ }^{[17]}$ is given in table 2 . 


\section{INTERNATIONAL JOURNAL of RESEARCH -GRANTHAALAYAH \\ A knowledge Repository}

Science

Table 2: Composition of jute fiber

\begin{tabular}{|l|l|}
\hline Composition & Weight in percentage (\%) \\
\hline Lignin & $12-14$ \\
\hline$\alpha$ - cellulose & $58-63$ \\
\hline Hemicelluloses & $21-24$ \\
\hline Minor constituents & $2-4$ \\
\hline
\end{tabular}

When water flows through these capillaries, water molecules are absorbed by cotton and jute material, due to their structure and chemical nature. In order to reduce the surrounding air temperature of working motor, the quantity of water absorbed by the capillaries differs with time which is shown in table3.

Table 3: Quantity of water absorbed by the capillaries with time

\begin{tabular}{|l|l|}
\hline $\begin{array}{l}\text { Time of operation of three phase induction } \\
\text { motor (minutes) }\end{array}$ & Quantity of water absorbed of capillaries (ml) \\
\hline 40 & 450 \\
\hline 60 & 675 \\
\hline 120 & 1350 \\
\hline 180 & 2025 \\
\hline
\end{tabular}

Figure 3 shows the working of NWCC method applied on three phase induction motor. Funnel is used to transfer water from storage tank which can be managed through tap arrangement. Funnel is joined with a bunch of capillary tubes and same capillaries are attached to the outer surface of jacket. Inlet water from capillary tube is uniformly distributed in the capillaries of jacket through absorption process. Water is further absorbed by the layer of cotton which cools the passage of air in between motor casing and jacket. Natural cooling phenomenon takes place when passage air molecules come in contact with the wet layer of jacket; simultaneously there is reduction of surrounding temperature. This heat removal process from motor is beneficial for improving the temperature withstanding capacity of motor as well as life of insulation used. 


\section{INTERNATIONAL JOURNAL of RESEARCH -GRANTHAALAYAH A knowledge Repository}

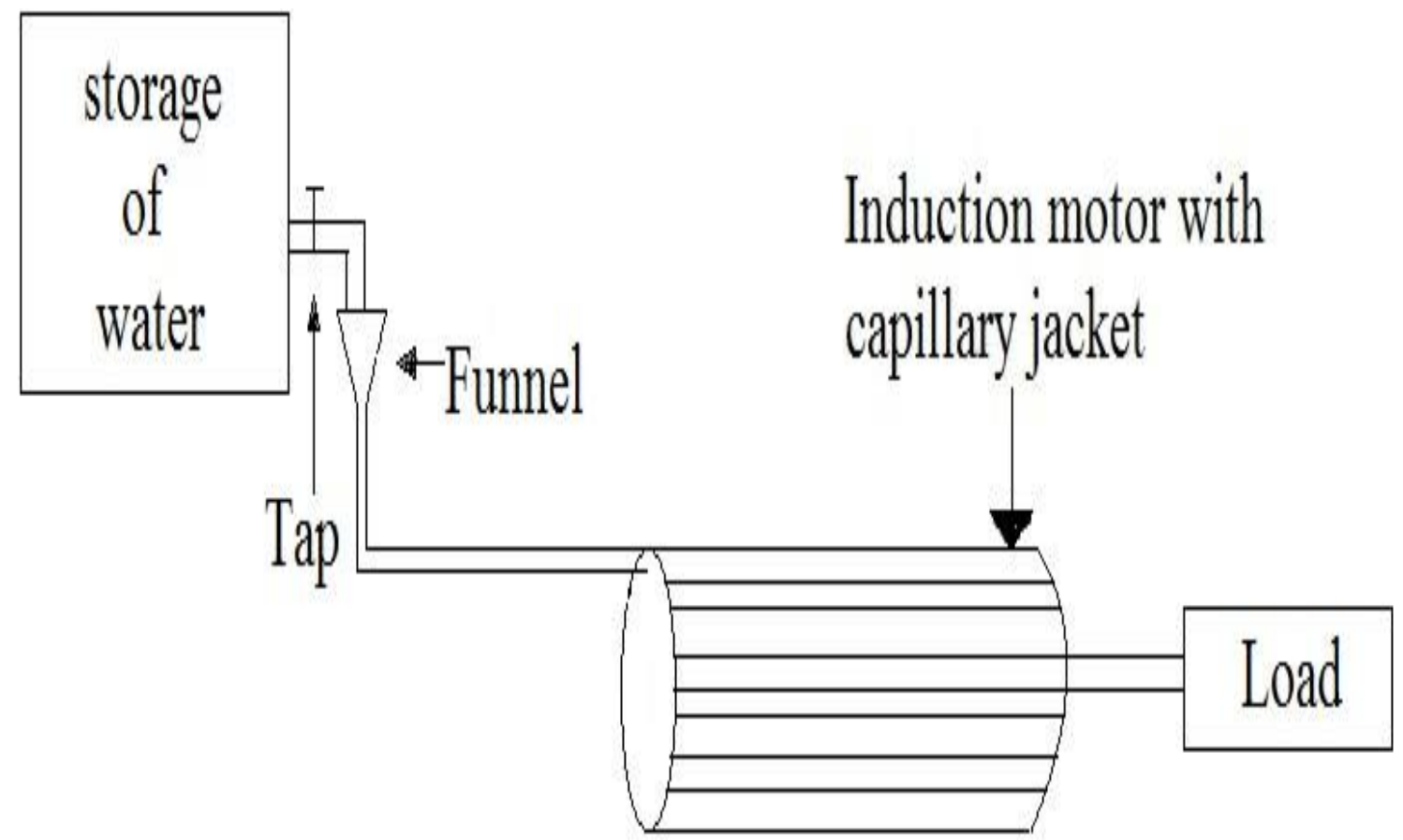

Figure 3: working of NWCC method

\section{RESULT AND DISCUSSION}

Heat Run Test: This test is done on three phase squirrel cage induction motor to determine the part of input energy which is dissipated as heat due to the losses. Heat run test is conducted on the motor as per IEC 60851. Temperature of motor stator winding is measured with standard digital temperature indicator. Tests were conducted on the motor with applying NWCC method and without NWCC method. Table 4 shows the temperature of stator winding in both cases with respect to time.

Table 4: Temperature of stator with and without NWCC method with time.

\begin{tabular}{|l|l|l|}
\hline Time in minutes & $\begin{array}{l}\text { Temperature of motor } \\
\text { without NWCC method in }{ }^{0} \mathrm{C}\end{array}$ & $\begin{array}{l}\text { Temperature of motor with } \\
\text { NWCC method in }{ }^{0} \mathrm{C}\end{array}$ \\
\hline 0 & 25.3 & 25.6 \\
\hline 2 & 26.7 & 26.1 \\
\hline 4 & 27.9 & 26.7 \\
\hline
\end{tabular}




\section{INTERNATIONAL JOURNAL of RESEARCH -GRANTHAALAYAH}

Science

A knowledge Repository

\begin{tabular}{|l|l|l|}
\hline 6 & 29.3 & 27.1 \\
\hline 8 & 30.9 & 27.6 \\
\hline 10 & 32 & 28.2 \\
\hline 12 & 33.2 & 28.8 \\
\hline 14 & 34.5 & 29.5 \\
\hline 16 & 35.9 & 30 \\
\hline 18 & 37.4 & 31.2 \\
\hline 20 & 39 & 32.4 \\
\hline 22 & 40.2 & 33.5 \\
\hline 24 & 41.6 & 34.7 \\
\hline 26 & 42.7 & 35.8 \\
\hline 28 & 44.2 & 37 \\
\hline 30 & 45.3 & 38.3 \\
\hline 32 & 46.6 & 39.5 \\
\hline 34 & 48.1 & 40.7 \\
\hline 36 & 49.3 & 41.8 \\
\hline 38 & 50.7 & 42.9 \\
\hline 40 & 52.2 & 44.1 \\
\hline & & \\
\hline & & \\
\hline
\end{tabular}

Figure 4 shows the graphical comparison of temperature variation of stator when test is performed with and without NWCC method. The result shows that there is satisfactory performance of NWCC method and temperature is reduced by $8^{\circ} \mathrm{C}$. 

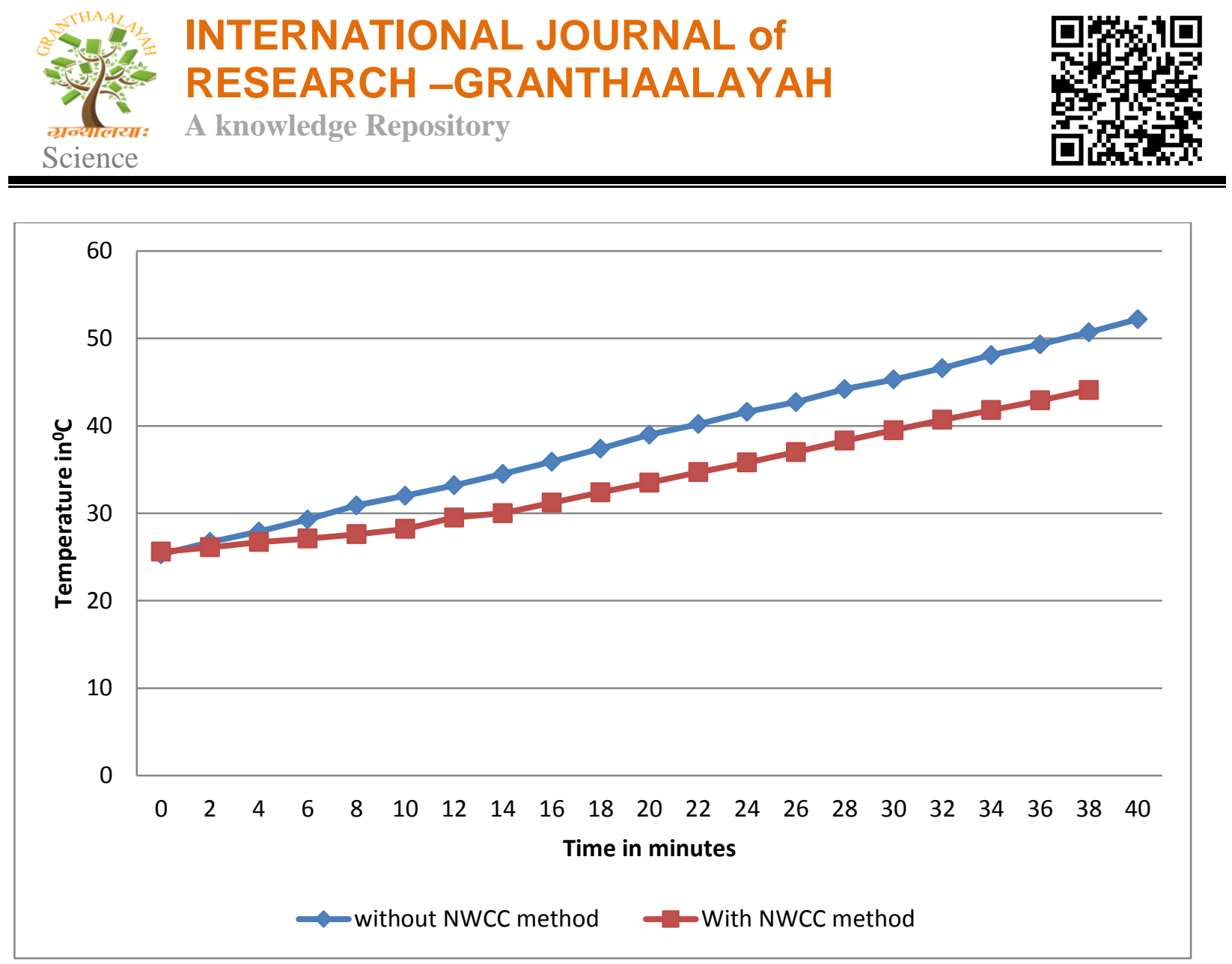

Figure4: Temperature variation of stator with and without NWCC method

Perhaps increase in thermal withstanding capacity of three phase induction motor by adopting NWCC method from experimental result performed on it, for 40 minutes can be determined as follows.

$\frac{\left(\mathrm{T}_{\text {without }}-\mathrm{T}_{\text {with }}\right) * 100}{\mathrm{~T}_{\text {without }}}$

$\mathrm{T}_{\text {without }}$ presents final temperature of motor without applying NWCC method in ${ }^{0} \mathrm{C}, \mathrm{T}_{\text {with }}$ presents final temperature of motor with applying NWCC method in ${ }^{0} \mathrm{C}$

$$
\begin{gathered}
=(52.2-44.1) * 100 \\
52.2 \\
=15.5 \%
\end{gathered}
$$

This shows that TWC of three phase induction motor is increased by $15.5 \%$. 


\section{INTERNATIONAL JOURNAL of RESEARCH -GRANTHAALAYAH \\ A knowledge Repository}

Science

\section{CONCLUSION}

In this paper, the stator and core temperature of a $1.1 \mathrm{~kW}$ three phase squirrel cage induction motor is lowered by means of NWCC method. It is shown that when NWCC method is applied the stator temperature decreases which increases the thermal withstanding capacity of insulation as well as life of motor. The impact of cooling on the thermal withstanding capacity of the motor was presented and by experimental analysis it is increased by $15.5 \%$.

It should be noted that the method used in this paper is of low cost and consumes less water. It does not require any external energy for cooling. Materials used to prepare apparatus for this method are easily available. NWCC method is highly effective due to high specific heat capacity of water and high heat transfer coefficients.

\section{REFERENCES}

[1] R.Beguenane and M.E.H.Benbouzid, Induction Motors Thermal Monitoring by Means of Rotor Resistance Identification, IEEE Transactions on Energy Conversions, Vol. 14, No. 3, 1999, 566570.

[2] Mendes, A.M.S., Lopez Fernandez, X.M. and Marques Cardoso, A.J., Thermal Performance of a Three Phase Induction Motor Under Fault Tolerant Operating Strategies, IEEE Transactions on Power Electronics, Vol. 23, No. 3, 2008, 1537-1544.

[3] K.G. Bante, S.g. Tarnekar and D.R. Tutakane, AC Motor Cooling System Analysis Based on Application Case Study, International Journal of Engineering Inventions, Vol. 2, No. 8, 2013, 915.

[4] M. Sikora, R. Vilach and P. Navratil, The Unusual Water Cooling Applied on Small Asynchronous Motor, Engineering Mechanics, Vol. 18, No. 2, 2011, 143-153.

[5] Borges, S.S., Cezario, C.A. and Kunz, T.T., Design of Water Cooled Electric Motors Using CFD and Thermography Techniques, ICEM 2008, $18^{\text {th }}$ International Conference on Electrical Machines, Vilamoura, 2008.

[6] Kral, C., Haumer, A. and Bauml, T., Thermal Model and Behaviour of Totally Enclosed Water Cooled Squirrel Cage Induction Machine for Traction Applications, Industrial Electronics, Vol. 55, No. 10, 2008.

[7] Caricchi, F., Crescimbini, F., Di Napoli, A. and Marcheggiani, M., Prototype of Electric Vehicle Drive with Twin Water cooled Wheel Direct Drive Motors, Power Electronics Specialists Conference, $27^{\text {th }}$ Annual IEEE, Baveno, 1996.

[8] S.L. Ho and W.N. Fu, Analysis of Indirect Temperature Rise Test of Induction Machine Using Time Stepping FEM, IEEE Transactions on Energy Conversions, Vol. 16, No. 1, 2001, 55-60. 


\section{INTERNATIONAL JOURNAL of RESEARCH -GRANTHAALAYAH \\ A knowledge Repository}

Science

[9] T.F. Chan, A Method to Determine the Temperature Rise of Induction Motors, International journal of Electrical Engineering Education, Vol. 27, 1990, 45-52.

[10] R. Findlay, N. Stranges and D.K. Mackay, Losses Due to Rotational Flux in Three Phase Induction Motor, IEEE Transactions on Energy Conversions, Vol. 9, 1994, 543-549.

[11] C. A. Hernandez-Aramburo, T. C. Green and A.C. Smith, Estimating Rotational Iron losses in an Induction Machine, IEEE Transactions on Magnetics, Vol. 39, No. 6, 2009, 3527-3533.

[12] C. A. Hernandez-Aramburo, T. C. Green, and A. C. Smith, Assessment of Power Losses of an Inverter-Driven Induction Machine with its Experimental Validation, IEEE Transaction on Industrial Applications, Vol. 39, July-Aug. 2003, 994-1004.

[13] L.I. Zhu and X.J. Zheng, A Theory for Electromagnetic Heat Conduction and Numerical Model Based on Boltzmann Equation, International Journal of Nonlinear Science and Numerical Simulation, Vol. 7, No. 3, 2006, 339-344.

[14] Y. Huai, R.V.N. Melnik and P.B. Thogersen, Computational Analysis of Temperature Rise Phenomena in Electric Induction Motors, Applied Thermal Engineering, Vol. 23, No. 1, 2003, 779795.

[15] R. Siegel and J.R Howell, Thermal radiation heat transfer, $3^{\text {rd }}$ ed., Hemisphere Publication Co. Washington; 1992, 119.

[16] B. Baptista, A. Mendes, S. Cruz and A. Cardoso, Temperature Distribution Inside a Three Phase Induction Motor Running with Eccentric Airgap, Electrical Review, Vol. 8 No. 1, 2012, 9699.

[17] R.Masoodi and K.M. Pillai, A Study on Moisture Absorption and Swelling in Bio-Based JuteEpoxy Composites, Journal of Reinforced Plastics and Composites, Vol. 31, No. 5, 2012, 285-292. 